\title{
EDUCAÇÃO GEOGRÁFICA E O ESTUDO DA CIDADE E DO URBANO EM SÃO GONÇALO - RJ: ATIVIDADES DE APRENDIZAGEM DOS DOCENTES E DISCENTES
}

\author{
La Educación Geográfica y el Estudio de la Ciudad y el Urbano en São Gonçalo - RJ: las \\ actividades didácticas de los profesores y los estudiantes
}

Ana Claudia Ramos Sacramento Prof. a Adjunta do Departamento de Geografia da FFP-UERJ anaclaudia.sacramento@hotmail.com

\author{
Aline Mello Campos

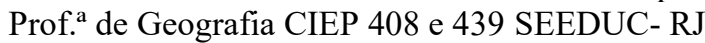 \\ amellocampos@yahoo.com.br
}

Fabiana Sanches

Prof. a de Geografia CIEP 439 SEEDUC- RJ

fabi-sanches@oi.com.br

Jupiara de Jesus Pereira da Silva

Prof. a de Geografia CIEP 439 SEEDUC- RJ

jupiarajpsgeografia@gmail.com

Artigo recebido em 05/02/2016 e aceito para publicação em 03/03/2016

DOI: $10.12957 /$ tamoios.2016.21441

Resumo

Resumen
A cidade, enquanto organização espacial nos fornece múltiplas leituras do espaço vivido, da territorialidade, do lugar do cidadão e das paisagens impressas da sociedade. Pensar como ensinar a cidade e o urbano possibilitam aos professores e aos alunos reconstruírem sua própria espacialidade, tomando consciência espacial dos aspectos sociais e físicas que são próprias da cidade onde vivem. Este artigo teve como objetivo analisar a relação de ensinar e de aprender sobre a cidade de São Gonçalo por alunos e professores de geografia dos Ensinos Fundamental II e Médio da rede pública, desenvolvido dentro do projeto de ensino público financiado pela FAPERJ. Assim, desenvolver conjuntamente, atividades que promovam a discussão sobre a importância da cidade de São Gonçalo como um objeto de estudo, é possibilitar a compreensão das práticas sociais dos estudantes. Desta maneira, a orientação metodológica utilizada foi a pesquisa ação, por meio das ações realizadas pelos sujeitos do processo de ensino e aprendizagem. Como resultados finais, percebe-se que a partir da apresentação de algumas atividades de aprendizagens construídas ao longo da pesquisa possibilitaram aproximar os conteúdos dos estudantes de sua realidade, envolvendo conteúdos como de cartografia, de relevo, dentre outros propiciando uma leitura espacial da cidade.

Palavras-chave: Educação Geográfica, Cidade, Urbano, Atividades de Aprendizagem.

La ciudad, mientras que la organización espacial nos proporciona múltiples lecturas del espacio vivido, la territorialidad, el lugar de los ciudadanos y los paisajes impresos de la sociedad viva. Piensar cómo enseñar la ciudad y lo urbano permite a profesores y estudiantes a reconstruir su propia espacialidad que le son propias a las ciudades en las que viven. Este artículo tiene como objetivo analizar la relación de la enseñanza y el aprendizaje sobre la ciudad de São Gonçalo por los estudiantes y los profesores de la geografía de Primaria y Secundaria de red pública, desarrollado en proyecto de educación pública financiada por FAPERJ. Así desarrollar, actividades para promover la discusión acerca de la importancia de la ciudad como objeto de estudio, es posible la comprensión de las prácticas sociales de los estudiantes. Por lo tanto, la orientación metodológica se utilizó la investigación-acción, a través de las acciones de los sujetos del proceso de enseñanza y aprendizaje. Al final, se puede observar que la presentación de algunas de las actividades construidas permitió acercarse a los contenidos de su realidad de los estudiantes, con la participación de contenido como cartografía, relieve, entre otras proporcionando una lectura espacial de la ciudad.

Palabras claves: Educación Geográfica, Ciudad, Urbano, Actividades de Aprendizaje. 


\section{INTRODUÇÃO}

Estudar a cidade e o urbano possibilita um outro olhar sobre as dimensões socioespaciais uma vez que os estudantes e os professores, em sua maioria, vivenciam as práticas socioespaciais da cidade em todos os aspectos: como moradia, como trabalho, como lazer e outros. Desta forma, pensar a cidade e o urbano como um conteúdo dentro dos conteúdos da geografia é uma forma de articular as escalas mundiais, nacionais, regionais e locais ao dar sentido a um determinado conteúdo.

Os professores, nas suas práticas de trabalho, têm consciência sobre os seus atos de ensinar, pois constroem o conhecimento por meio dos conceitos e conteúdos organizados didaticamente em sala de aula. Esta é a materialização dos seus saberes sobre um determinado tema, a partir daí os alunos se apropriam desses saberes.

$\mathrm{O}$ ato de refletir e racionalizar sua prática, bem como pensar a cidade como um objeto de estudo possibilita, a análise de conceitos que desenvolvam raciocínio, consciência e organização espacial nos alunos, analisando a importância da Geografia para compreensão da consciência espacial.

O objetivo este artigo é compreender algumas ações didáticas desenvolvidas pelos professores e estudantes do CIEP 439- Luiz Gonzaga Junior, bairro Luis Caçador - SG discutindo elementos da cidade e do urbano como forma de conteúdo para pensar o ensino de Geografia

Sobre a cidade e o urbano, autores como LEFEBVRE (1999, 2001), SOUZA (1996, 2000, 2011), SILVA (2012) possibilitam uma discussão teórica sobre o tema, assim como as autoras CALLAI (2005, 2006), CASTELLAR (2005, 2011), CASTELLAR e MORAES (2010), CAVALCANTI $(2005,2012)$, contribuem para a compreensão da importância do ensinar geografia, sobre os estudos a respeito das ações didáticas dos professores sobre cidade e urbano a discussão de LIBÂNEO (2009, 2007), MEIRIEU (1998), ZABALA (2007) ao discutirem sobre as atividades teórico-práticas na construção e no processo de ensinar - a aula; a metodologia de pesquisa a partir de THIOLLENT (2007) tendo como concepção teórico-metodológica a pesquisa-ação, nossa intenção é mostrar uma possibilidade de uma ação efetiva entre o pesquisador/sujeito-objeto de estudo, não sendo uma pesquisa precisa, pois permitem aos envolvidos dizerem e fazerem sobre algo.

Para tanto, o trabalho está dividido em três momento: o primeiro na qual discute-se a questão da importância do estudo da cidade e do urbano para as aulas de geografia; no segundo as orientações metodológicas que orientaram o trabalho a partir da pesquisa ação e no terceiro a cidade como conteúdo de ensino por meio das atividades didáticas desenvolvidas pelas professoras, bolsistas e estudantes nos quais nos mostram a importância de pensar os conteúdos relacionados com as espacialidades dos lugares vividos dos estudantes.

\section{A IMPORTÂNCIA DIDÁTICA DO ESTUDO DA CIDADE E DO URBANO}

A análise sobre prática pedagógica requer de si reflexão, crítica e constante criação e recriação do conhecimento e das metodologias de ensino, o que pressupõe uma atividade de investigação permanente que necessita ser apreendida e valorizada.

Meirieu (1998) destaca que as estratégias de aprendizagem representam a aprendizagem em ação, que pode ser caracterizada como uma seqüência de operações de assimilação dos dados e operações de tratamento dos dados. Essas estratégias fazem parte do processo de mediação do conhecimento. Libâneo (2009) trabalha a forma como se estrutura e como funciona a atividade de aprendizagem, elementos como o desejo, as necessidades, os 
motivos, os objetivos, as ações e as operações que constituem modos de internalização dos conhecimentos para que os alunos se relacionem com o mundo em que vive.

É importante entender o significado da aprendizagem e perceber como se é mediado o conhecimento sobre a necessidade de os professores construírem suas atividades, já que é a partir das suas concepções didático-pedagógicas, de acordo com a faixa etária e séries, as atividades desenvolvidas.

As metodologias e as didáticas da Geografia em seus múltiplos contextos e linguagens são importantes para pensar a cidade como objeto de estudo, as relações físico-naturais, as concepções do estudo do meio, as concepções cartográficas, os recursos digitais no ensinar geografia, os jogos, que nos permitem mediar o conhecimento dos conceitos geográficos que passam a ser a forma como os alunos compreendem, como os fenômenos se especializam, segundo CALLAI (2005, 2006), CASTELLAR (2005 2011), CASTELLAR e MORAES (2010), CAVALCANTI (2005a, 2005b, 2011).

As ações didáticas são relacionadas pela forma como são desenvolvidas as diferentes concepções de ensino e de aprendizagem para que os estudantes aprendam um determinado saber. (Meirieu, 1998,p. 51) destaca que os mesmos, ao construir o conhecimento, precisam estar atentos, ler e escutar, receber informações que sejam relevantes, isto quer dizer que, os professores precisam construir e compreender os signos e os fenômenos, para promover atividades de aprendizagem que façam-os a organizarem cognitivamente o saber.

Para entender os fenômenos, é necessário, ensinar os conceitos para a compreensão do desenvolvimento e da organização espacial por meio das mudanças técnicas-científicas, bem como a formação sócio-econômica, promovendo uma consciência espacial crítica em relação à construção e à transformação das múltiplas análises espaciais que precisam ser entendidas como outras representações do mundo em que vivemos, sendo estudada de formas articuladas, (Moreira, 2008), (Santos, 2002).

Para dar caráter científico ao mundo em que vive-se os conceitos são primordiais para os alunos saírem do senso comum e contemplar as concepções geográficas sobre determinados objetos e lugares, destacadas por Moreira (2008, p. 116-117):

Perceber um fenômeno em sua dimensão geográfica é assim primeiramente
localizar, distribuir, conectar, medir a distância, delimitar a extensão e verificar a
escala de sua manifestação na paisagem. A forma como o fenômeno aparece no
espaço é a do objeto espacial, a exemplo da fábrica no fenômeno econômico, da
igreja no fenômeno cultural e do parlamento no fenômeno político. Todo
conhecimento em geografia por isso começa na descrição da paisagem.

Para ler os fenômenos, os alunos precisam ter uma lógica de organização da aprendizagem, realizar algumas etapas de como eles percebem as diferentes formas de análise sobre uma dada realidade. Desta maneira, é importante que as ações didáticas dos professores estejam sempre direcionadas a pensar na construção dos conceitos, já que se possuem elementos cognitivos necessários para entendê-los. Para o autor, para se conhecer a Geografia precisa fazer a descrição da paisagem, pois é a partir dela que se desvenda os outros aspectos característicos do espaço, já que a paisagem é a materialização concreta dos fenômenos e dos objetos.

Assim, precisa-se fazer com que o aluno reconheça, analise e reflita sobre sua realidade, tendo como sentido básico, educar esse aluno geograficamente. É fazê-lo perceber os fenômenos geográficos localizados em um determinado espaço, saber descrever e analisar as diferentes formas das paisagens de um determinado lugar e o meio no qual ele está inserido, também de forma cartográfica.

Zabala (2007) traz contribuições significativas para pensar a importância e a forma de elaboração da atividade de ensino, pois permite a organização de diferentes práticas dentro 
dela. Segundo o autor, estas são "um conjunto de atividades ordenadas, estruturadas e articuladas para a realização de certos objetivos educacionais, que têm um princípio e um fim, conhecidos tanto pelos professores como pelos alunos" (p. 18). Sendo assim, não pode ser desenvolvido qualquer tipo de sequencia, mas sim, a que possibilitará os conceitos e os conteúdos geográficos para a formação da consciência espacial.

A Geografia Escolar possibilita aos alunos um pensamento crítico, buscando a construção da cidadania, do pensar seu lugar, seu espaço nacional e seu espaço mundial e pensar a relação da luta entre classes. A importância de saber ler, interpretar, localizar-se por meio dos mapas nos orientam para os lugares ou para onde se localiza as coisas no espaço.

Desta forma, o ponto de vista para se estudar a geografia: olhando o espaço, olhando em volta, percebendo o que existe, sabendo analisar as paisagens como o momento instantâneo de uma história que vai acontecendo. Essa é a leitura do mundo da vida, mas que não se esgota metodologicamente nas características de uma geografia viva e atual. (CALLAI, 2006)

Por isso, a Educação Geográfica contribui para pensar as questões práticas do cotidiano, bem como, uma interpretação dos fenômenos geográficos em que os professores envolvam os alunos para que eles compreendam o significado desses em seu espaço vivido, CALLAI (2005), LEFEBVRE (1999, 2001), MOREIRA (2008) SANTOS (2002) para saber como agir, saber diferenciar as paisagens; os elementos físicos e humanos da sua rua, do seu bairro, da sua cidade; ler mapas, signos e símbolos; que tem concepções lógicas de ordenamento espacial.

Pensar a cidade e o urbano de seu lugar segundo SOUZA $(1996,2000,2011)$ é destaca a importância da cidade como um "espaço social", um produto das relações sociais e um condicionador dessas relações. É nesse sentido que a Educação Geográfica precisa estabelecer relações geográficas para fazer com que o aluno compreenda sua espacialidade nessas dimensões, partindo de alguns elementos necessários que estimulem sua capacidade cognitiva. Entendendo a cidade como um espaço educativo e apreendendo com as diferentes formas de ensinar a cidade.

A cidade, em suas múltiplas relações sociais, econômicas, históricas, geográficas em constante transformação, exige uma compreensão contínua da organização e estruturação das novas dinâmicas do espaço. Não por outro motivo, inúmeros autores destacam a importância de analisar aas concepções urbanas como ABREU (1997); LEFEBVRE (1999, 2001); SOUZA (2011), dentre outros, para que se compreenda as diferentes mudanças ocorridas a partir das reorganizações espaciais de suas funções, formas, conteúdos e ações sociais. A cidade representa a obra da história construída por seus sujeitos, ou simplesmente, a ação da sociedade que vive, produz e reproduz esse espaço.

Lefebvre (2001) afirma que a cidade é um objeto construído socialmente com diversas funcionalidades que se revelam ao longo da história, em suas diferentes formas e funções. A sociedade constitui novos elementos como novas técnicas, concepções arquitetônicas, ideológicas e políticas, e outros que possibilitaram o desenvolvimento de um processo urbano. A cidade e o urbano seriam uma forma dialética que se interagem sobre uma forma material o prático sensível - que pode viabilizar ou não a forma urbana.

Assim, o conhecimento sobre a cidade e os aspectos urbanos é um dos elementos fundamentais para se ensinar Geografia, pois, este é o espaço vivido da maioria da população, o que permite dialogar com os fenômenos geográficos especializados nesses ambientes. Pensar o ensino da cidade e os processos do urbano na educação geográfica requer o reconhecimento de uma ação didática voltada para a construção do conhecimento de aluno de forma significativa e ativa.

Ora, trabalhar a cidade e todo o seu processo de urbanização, assim como os elementos que a caracteriza, sua dinâmica com os alunos, se torna fundamental para o pensar 
a cidade, tendo em vista as concepções de produção do espaço urbano, conforme Cavalcanti (2012). Faz-se necessário também pensar o espaço urbano e sua contradição entre produção e consumo que está baseada em uma lógica capitalista que segrega os espaços, levando em conta também as questões ambientais.

Articular com os alunos a questão de cidadania, o ter o direito a cidade, de morar, lazer, educação, trabalho, de produzir, circulação, de vivenciar os seus espaços, de manifestar sua cultura, que todos somos agentes ativos na formação e modificação do espaço urbano e que temos direitos como cidadãos de vivenciar esses espaços, lutar por esses direitos. A escola constitui elemento fundamental para a formação da cidadania, além de ajudar os estudantes a fazer essa leitura.

A cidade é educadora, ela forma valores, comportamentos, ela informa com sua espacialidade, com seus sinais, com suas imagens, com sua escrita. Ela também é um conteúdo a ser apreendido por seus habitantes. No entanto, as possibilidades de uma leitura mais abrangente da cidade dependem de uma formação de cidadão. (CAVALCANTI, 2012, p.74)

Dessa forma, o ensino de Geografia está estritamente ligado à formação de cidadania, pois constrói e reconstrói conhecimentos, capacitando os alunos a terem uma noção de mundo em que vivem e uma das instancias formadoras da cidadania são suas práticas cotidianas. Pensar como sua consciência pode modificar a forma de educar geograficamente, como a mediação pode articular a aula, orientando o saber do aluno. Para isso, as concepções didáticas são extremamente importantes para perceber as diferenças forma de ensinar.

Sendo assim, os professores desenvolvem uma de suas funções que é fazer com que o aluno se conscientizasse de seu papel de cidadão e de conhecer como "saber pensar" o espaço social produzido pela sociedade dentro de uma compreensão do seu espaço de vida, o que ela significa e qual transformação desse que se configura em lugar ou território.

\section{ORIENTAÇÕES METODOLÓGICAS}

Para o desenvolvimento das atividades de aprendizagens na escola por docentes e discentes, a base metodológica foi a pesquisa-ação, por acreditar que esta seja fruto de uma relação dinâmica, uma vez que os sujeitos também são os objetos deste trabalho.

Os teóricos ligados à pesquisa qualitativa em educação têm produzido ações diferenciadas na tentativa de orientar os processos de uma pesquisa e de se pensar os meios que ajudem a entender como organizar procedimentos teórico-metodológicos necessários para uma efetiva orientação metodológica. Desta forma, produzir maneiras que o pesquisador entenda e análise, principalmente a realidade social da escola, sua dinâmica e os sujeitos imbuídos, no processo de construção dos conhecimentos escolares.

De acordo com Menga e André (1986) Thiollent (2007) esta possibilita uma forma interpretativa, analítica de observação e produção de materiais para refletir como o ato do trabalho docente. Este que está materializado na elaboração didática na sala de aula, no caso da nossa pesquisa, dos conceitos e dos conteúdos geográficos.

A ação é um movimento duplo, e à medida que se torna significativa ao processo escolar, não é só executada pelo pesquisador, mas por todos os envolvidos na pesquisa. Segundo Thiollent (2007), esta tem alguns aspectos importantes: a) há uma ampla e explícita interação entre pesquisadores e pessoas implicada na situação investigada; desta interação resulta a ordem de prioridade dos problemas a serem pesquisados e soluções a serem encaminhadas sob forma de ação concreta; objeto de investigação não é constituído pelas pessoas e sim pela situação social e pelos problemas de diferentes naturezas encontrados nesta; o objetivo a pesquisa-ação consiste em resolver, ou pelo menos, em esclarecer os 
problemas da situação observada; há, durante o processo, um acompanhamento das decisões, das ações se de toda a atividade intencional dos atores da situação; a pesquisa não se limita a uma forma de ação: pretende-se aumentar o conhecimento dos pesquisadores e $\mathrm{o}$ conhecimento ou nível de consciência do grupo a ser pesquisado.

Estes aspectos possibilitam-nos pensar no desenvolvimento de uma pesquisa, principalmente, porque se deseja manter um diálogo aberto entre o pesquisador e os sujeitos, buscando por possíveis soluções, repesando as prátias efetivas na sala de aul. Por isso, analisar as ações didáticas docentes e entender como eles desenvolvem os conhecimentos dos alunos são importante para refletir sobre a mediação dos conceitos no ensino de Geografia.

Desse modo, a contribuição da pesquisa-ação é fundamental para que ocorra esse movimento uma vez que o sujeito se torna pesquisador. Thiollent (2007) situa a pesquisa-ação na escola ao mencionar a importância dessa metodologia de trabalho, pois permite a construção de conhecimento de todas as partes da pesquisa, o pensar e a reflexão dos objetos que estão em volta e a melhoria social e educativa dos sujeitos. É uma metodologia dinâmica e ativa, os agentes sempre estão em processo de ação, de construção, de produção. Para realização das atividades:

a) Oficina de discussão de textos com professores e os bolsistas;

b) Construção de oficinas e atividades didáticas entre os professores e os bolsistas;

c) Consolidação do desenvolvimento das atividades didáticas e as oficinas com os discentes.

\section{SÃO GONÇALO COMO CONTEÚDO: AS AÇÕES DIDÁTICAS DOS DOCENTES E DISCENTE}

O estudo da cidade representa novas experiências de trabalho a respeito da vida cotidiana dos alunos e a forma como interpretam a tal realidade. Por meio dos conceitos e dos conteúdos vinculados a cidade e ao urbano, procura-se desenvolver atividades que estimulem o conhecimento geográfico.

A cidade de São Gonçalo vivencia processos de transformações visíveis ou não aos olhos daqueles que caminham por ela. Esta é fruto de uma dada história que ao longo do tempo foi modificada de acordo com os interesses das grandes corporações e dos poderes políticos que se apropriaram para construir os objetos técnicos constituindo outras paisagens e outras práticas sociais. Os espaços são organizados para atentar as demandas do capitalismo imobiliário que constroem e destroem as paisagens que ganham outros arranjos.

Com parte da Região Metropolitana do Rio de Janeiro, pode-se dizer que esta cidade é segregada. Um dos grandes problemas da maioria das cidades metropolitanas como enfatiza Silva (2012), é a pobreza social presente na paisagem, devido ao processo de modernização que exclui os menos favorecidos. Dessa forma, o reconhecimento das formas espaciais e sociais são elementos importantes a serem trabalhados em sala de aula, já que o município de São Gonçalo faz parte deste contexto.

O alto crescimento demográfico é um dos problemas agravantes nas regiões metropolitanas. Isso ocorre devido ao processo de atração populacional para estes municípios, à implementação de indústrias têxteis, de alimentos, dentre outras. Simultaneamente, ocorre o processo de urbanização duplo, por um lado pela implementação das indústrias e outras atividades econômicas e, por outro, pela expansão de residências, com presença de loteamentos, muitas das vezes clandestinos. Por exemplo, São Gonçalo é tem mais de um milhão de habitantes, é um caso, onde vários loteamentos aconteceram, bairros que foram 
criados sem infraestruturas. Desta forma, criando uma nova relação com o uso do solo urbano.

Com isso, aparecem as baixas condições de vida e o acesso à cidade, tais como, falta de saneamento básico, difícil acesso ao transporte público, ruas sem asfaltos, iluminação precária, dentre outros elementos que fazem parte do cotidiano da cidade, não excluindo disso a cidade de São Gonçalo que vivencia todos esses problemas do processo urbano caótico (SILVA, 2012).

Destaca Souza (2011), que os dois grandes conjuntos do problema urbano está na pobreza e na segregação residencial. Mas não só elas como também a degradação ambiental, o sistema de tráfego (os fluxos), serviços básicos e outros. Esses, problemas que permeiam a cidade afetam diretamente ao meio ambiente, pois com a falta de uma rede de esgoto, a maioria dos domicílios despejam seus dejetos em rios, encostas, mares afetando tanto aos animais que vivem nesses ambientes, ao pescadores e comunidades tradicionais que sobrevivem desses ambientes, e a própria cidade com aparecimento de insetos nocivos à saúde.

São Gonçalo, sendo uma cidade também com as dimensões físicas expressivas, tem como formas de relevo: morros isolados, serras e planícies. Os morros estão espalhados nas direções sul e oeste do município. A área das planícies localiza-se em sua quase totalidade na parte norte do município, na divisa com Itaboraí. Os mangues, suas praias e a baia de Guanabara que são poucos ou quase nada estudados, que foram apropriadas pela violência urbana (em decorrência do tráfico de drogas), pela moradia, pelos estaleiros, pelas indústrias, e outros que se apropriam das estruturas físicas da cidade, modificando-a causando impactos ambientais nos mangues e nas praias. Possui uma rede hidrográfica extensa, mas infelizmente, todos os rios do município sofrem intenso processo de assoreamento, recebendo também grande carga de esgotos domésticos.

A cidade de São Gonçalo está representada pelos diferentes elementos que a constituem os homens, as firmas, as instituições, o meio ambiente e a infra-estrutura que as modificam conforme sua necessidade de organizá-la. Esta cidade está impregnada das marcas que se expressam pelas relações sociais, pelas ações políticas que a caracterizam com as múltiplas possibilidades de articulação entre dos aspectos físico-naturais e seus impactos sobre as pessoas que vivenciam e caminham nestes lugares. ABREU (1997); LEFEBVRE (1999, 2001); SOUZA (2011).

Uma das questões mais presentes no campo da pesquisa dentro da ciência geográfica no ambiento escolar é como dar sentido aos conceitos e conteúdos geográficos nas práticas cotidianas dos estudantes. Outro ponto está voltado as diferentes metodologias de ensinar para que se rompa com um ensino voltado para a não prática cidadã. Além disso, analisar como os professores tem efetivado a construção da geografia escolar em sala de aula. Todos esses elementos têm fomentado estudos para que seja repensada as ações na escola em prol da melhoria da escola pública.

Segundo Sacramento e Falconi (2010) uma educação geográfica que supere as aprendizagens repetitivas e sem sentido, e passar a adotar outras práticas de ensino, investindo nas habilidades: análises, interpretações e aplicações em situações práticas; trabalhar a cartografia como metodologia para a construção do conhecimento geográfico, a partir da linguagem cartográfica; analisar os fenômenos em diferentes escalas; compreender a dimensão ambiental, política e socioeconômica dos territórios, dando dessa forma um caráter diferenciado ao currículo escolar.

Assim permitindo que o ensino de Geografia possibilite a compreensão de ações nos quais os professores devem ter para orientar seus trabalhos na busca de uma disciplina voltada em interpretar e analisar os fenômenos geográficos existentes no espaço. A concepção das aulas deve ser orientada em abordar de forma interativa os temas destacando os elementos 
relevantes na produção do conhecimento. CASTELLAR (2005 2011), CASTELLAR e MORAES (2010), CAVALCANTI $(2005,2012)$.

Desta maneira, criando condições para que estes entendem os fenômenos geográficos, no caso, que fazem a relação com o aprender sobre a cidade e o urbano, que ocorrem a sua volta. Esse processo se dá na medida em que o professor enquanto mediador organize e estruture a aula levando em consideração os conhecimentos prévios trazidos pelos alunos.

Segundo Meirieu (1998), os professores começam a organizar a atividade/ estratégia de aprendizagem, que em parte, se relaciona ao que o autor classifica como "diferenciação sucessiva", a qual pode ser regulada por uma simples observação da reação da turma, na qual os professores conservam o controle de toda a sua turma, mas esforça-se para variar sucessivamente as situações e as ferramentas

As estratégias de aprendizagem foram desenvolvidas para que os estudantes pudessem analisar o estudo da cidade e do urbano no cotidiano escolar. Uma das questões fundamentais dentro do ensinar Geografia é a elaboração das atividades que permitem o diálogo entre os estudantes, os professores e os saberes para construir o conhecimento. Pensar então como são ensinados os conteúdos e os conceitos devem ser um refletir constante na prática docente para que sejam compreendidas as diversas dinâmicas e as formas de aprendizagem que permitem aos estudantes apreenderem o conhecimento. (LIBÂNEO, 2007)

Ao pensar atividades de aprendizagem que trabalhem com a discussão da cidade e do urbano de São Gonçalo, seus elementos físico-naturais como conteúdo o que se quer com isso? Desenvolver atividades que possibilitam a articulação constante entre o conhecimento científico e o conhecimento prévio do estudante e trazer uma proposta de trabalho que promova a construção da geografia desta cidade a partir de outros conteúdos que são ministrados ao longo de ano e que são necessários para entender os fenômenos geográficos que são especializados em diferentes escalas.

As atividades de aprendizagem devem possibilitar que os estudantes aprendam sobre um determinado tema, conceito e conteúdo para que saibam ler e interpretar sobre aquilo que estão a sua volta, ou sobre aquilo que leem ou veem em outros ambientes. Segundo Zabala (2007, p. 29): "É preciso insistir que tudo quanto fazemos em aula, por menor que seja, incide em maior ou menor grau na formação de nossos alunos. "Desta maneira, o que se é produzido e pensado para a sala de aula deve ter o papel de formar os nossos estudantes para que eles apreendam o conhecimento.

Neste artigo, será apresentada algumas atividades de aprendizagem construída pelos docentes e bolsistas a fim de desenvolver aulas significativas para os estudantes relacionados os conteúdos e os conceitos a cidade e o urbano de São Gonçalo.

\section{1) Confecção de painel cartográfico sobre a Cidade}

Foi desenvolvida uma atividade na qual os estudantes deveriam representar ou localizar partes da cidade por meio da discussão cartográfica. Os mapas utilizados foram o mapa de Regiões de Governo e Municípios do Estado do Rio de Janeiro e o mapa da Região Metropolitana do Rio de Janeiro, dando destaque a localização do município de São Gonçalo e dos municípios fronteiriço a ele.

\section{ATIVIDADE 1: CONHECENDO OS BAIRROS DE SÃO GONÇALO}

Você conhece os bairros do seu município? 


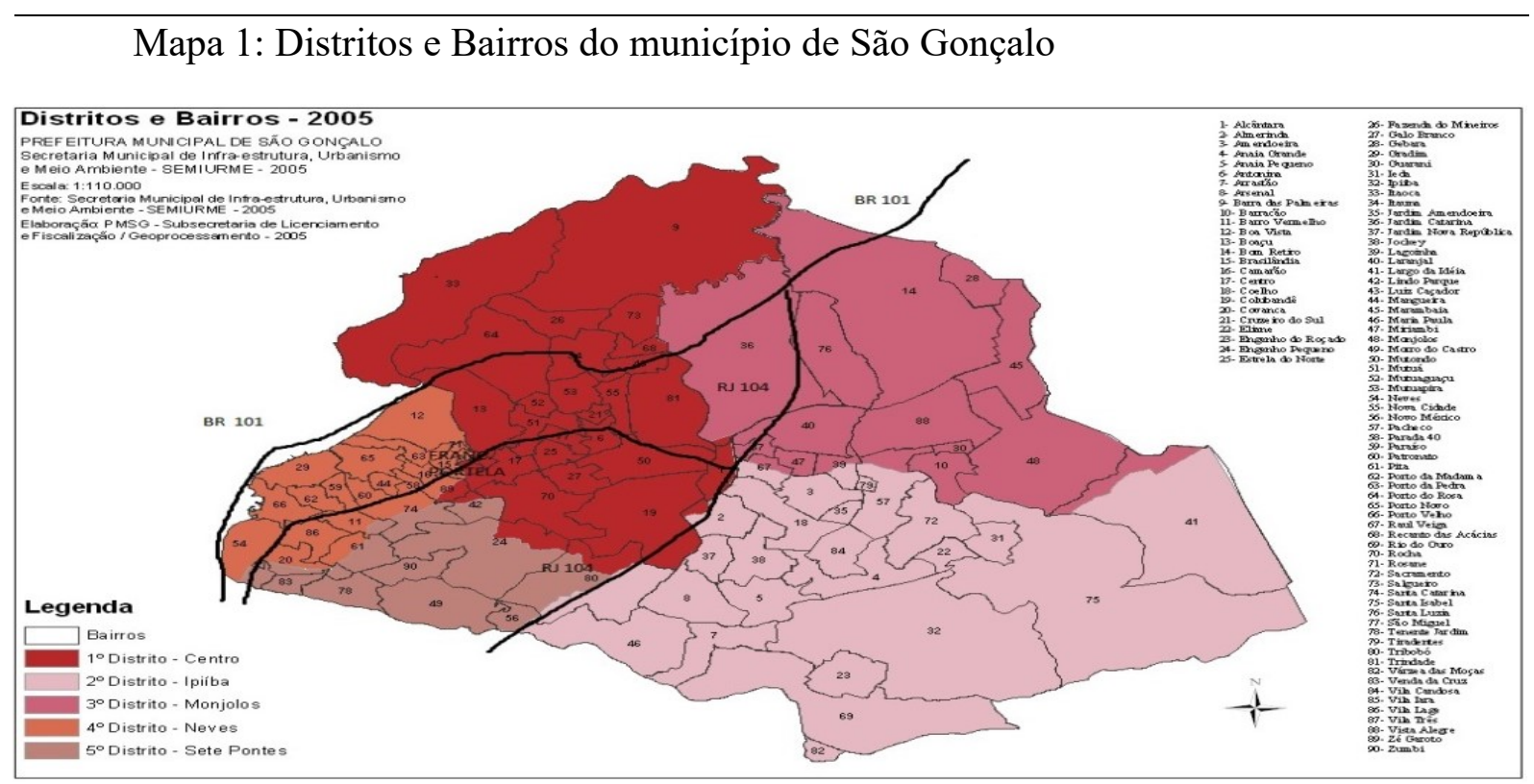

1) Escreva os nomes dos bairros que você conhece em São Gonçalo (colocar os números correspondentes).

2) Quais deles você já visitou e o que você fez ou faz nestes lugares?

3) Qual é o título do mapa?

4) Qual é a escala do mapa?

5) Qual é a fonte do mapa?

6) Qual é a legenda do mapa?

\section{ATIVIDADE 2: CONHECENDO A DIVISÃO POLÍTICA-ADMINISTRATIVA DE SÃO GONÇALO}

Você conhece o mapa de seu município? Este mapa representa um tipo de divisão administrativa. São Gonçalo é dividido por distritos.

Mapa 2: Distritos do município de São Gonçalo

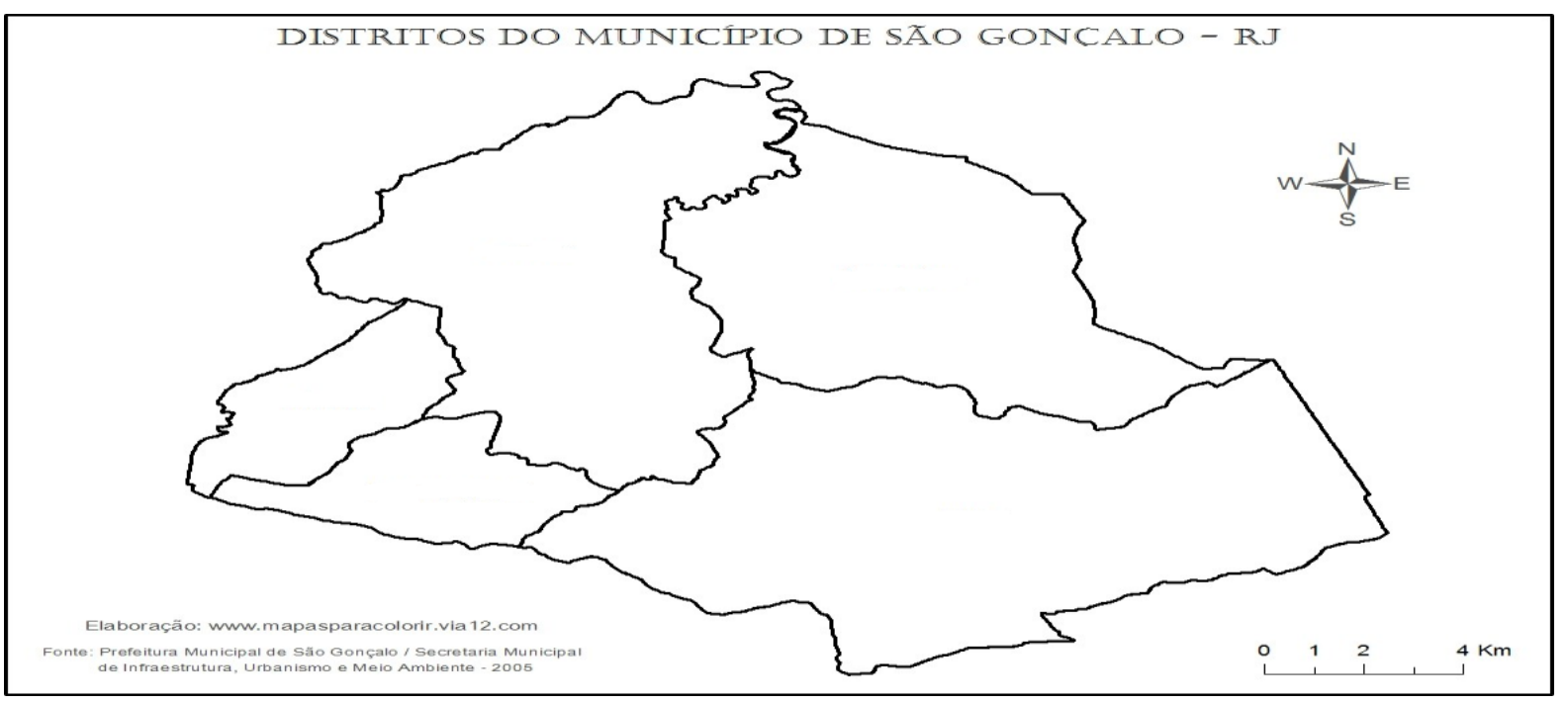


Escreva:

a) O nome dos distritos no mapa: $1^{\circ}$ Centro, $2^{\circ}$ Ipiiaba, $3^{\circ}$ Monjolos, $3^{\circ}$ Neves e $5^{\circ}$ Sete Pontes.

b) O distrito onde se localizam: casa e escola

c) Escreva a escala deste mapa:

d) Coloque no mapa de cor vermelha, as principais vias que você conhece (rua, estrada ou BR) que passam pelo município:

e) Qual é o título do mapa?

f) Qual é a escala do mapa?

g) Qual é a fonte do mapa?

h) Qual é a legenda do mapa?

\section{ATIVIDADE 3: CONHECENDO OS LIMITES DE SÃO GONÇALO}

Neste mapa, pode-se observar o município de São Gonçalo e os municípios limites. Mapa 3: Região Metropolitana do Rio de Janeiro -2014

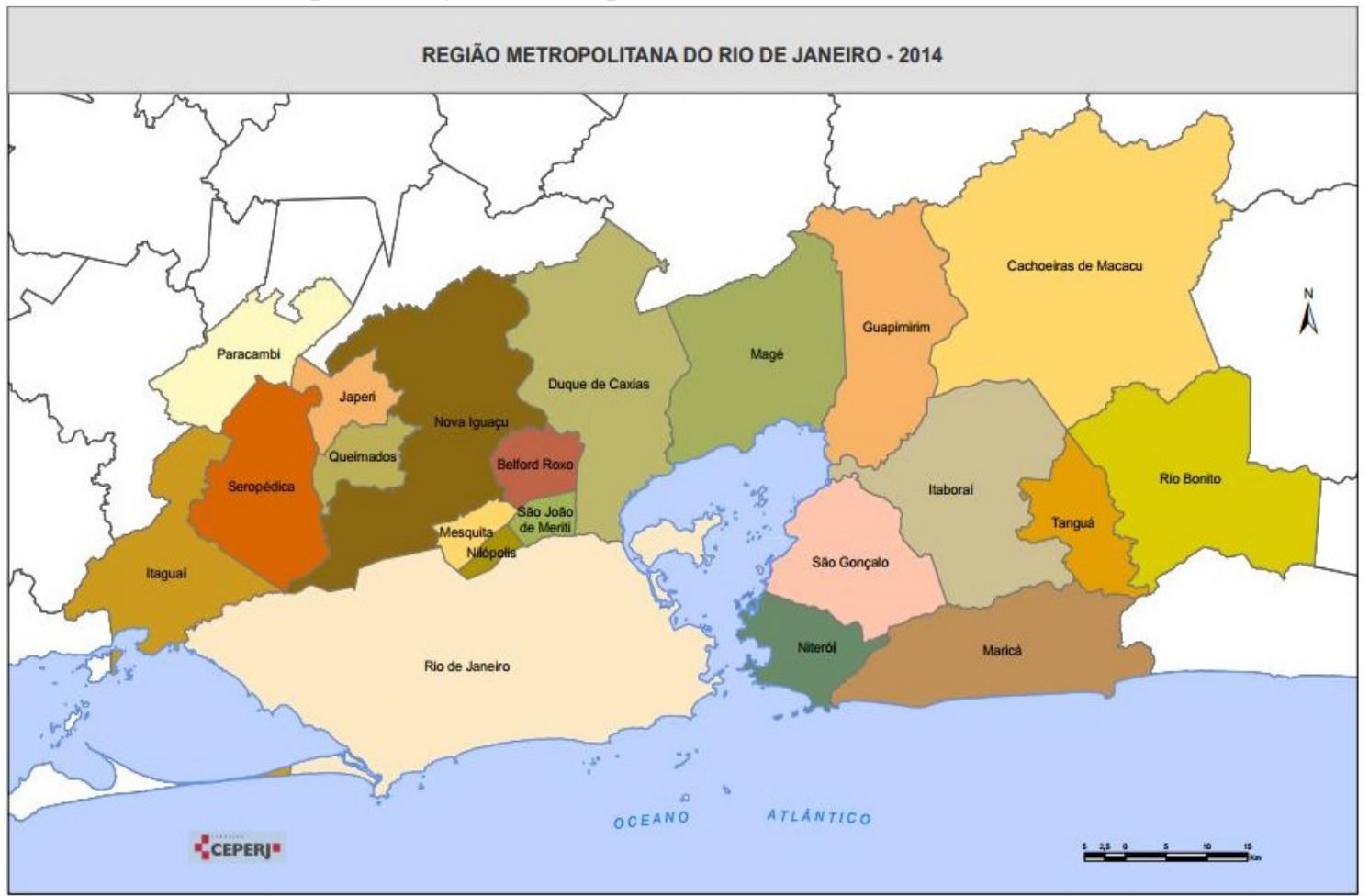

1) Circule os muncípios que fazem limites com município de São Gonçalo em caneta vermelha. Qual seria o seu limitea Oeste?

2) Você já visitou alguns desses municípios limites? Quais foram eles e o que fez lá?

3) Você conhece algum outro município, além dos limites do município de São Gonçalo? Escreva-os e o que fez lá?

4) Qual é o título do mapa?

5) Qual é a escala do mapa?

6) Qual é a fonte do mapa?

7) Qual é a legenda do mapa? 
Ficou evidente no decorrer da atividade, que mesmo sendo alunos do Ensino Médio, não conhecem o mapa do estado, não tem informações sobre a organização política do estado e também não percebem sua localização dentro do território do estado onde vivem. $\mathrm{Na}$ primeira atividade, os estudantes deveriam reconhecer os bairros da cidade e já tinham visitado alguns deles e outra parte das perguntas estão ligadas aos elementos do mapa. Chamou atenção da atividade que os estudantes conhecem muito pouco a cidade, geralmente vão a dois lugares específicos: o Centro da Cidade e o bairro de Alcântara porque são os bairros nos quais os serviços e a parte comercial tem mais dinâmica na cidade. Outros lugares mencionados têm a ver com visitas familiares.

Em relação aos elementos que compõem o mapa, as dificuldades em responder foram diversas o que permite compreender a falta de apropriação deste conhecimento tão importante para análise de mapas. Na segunda atividade, o reconhecimento do mapa políticoadministrativo da cidade por meio da divisão em distritos. O estudante deveria além de saber identificar os distritos, tinham que relacioná-los a cidade, além da atividade dos elementos do mapa. A dificuldade foi similar da atividade 1, os estudantes não conseguiram identificar os distritos, assim como da escola e da casa. Outra foi saber as primeiras vias de acesso da cidade.

$\mathrm{Na}$ atividade 3, a ideia era saber se os estudantes conheciam para além do município. A partir das respostas dadas boa parte dos estudantes conhecem Itaboraí ou Niterói. Fora do limite, poucos já foram ao Rio de Janeiro ou a outros municípios.

A partir de um diagnóstico preliminar foi possível perceber que as turmas da $1^{a}$ série do Ensino Médio apresentavam dificuldades de localização espacial, desde as orientações básicas através dos pontos de orientação e das linhas de localização até a compreensão de escalas. Havia dificuldade por parte dos alunos em perceber a variação da escala micro (local) a escala macro (global).

Partindo dessa dificuldade foi confeccionado um painel intitulado "Onde você está?" Esta atividade de aprendizagem foi pensada para que os estudantes a durou cerca de quatro horas-aula total de dois dias. O objetivo da proposta foi trabalhar a multidimensionalidade escalar, e a relação de interdependência entre o local e o global. Nas duas primeiras aulas, os alunos reuniram-se em grupos e coloriram de forma simples alguns mapas, destacaram a localização da escola e a identificaram com legenda. Nas duas últimas, os alunos confeccionaram um painel.

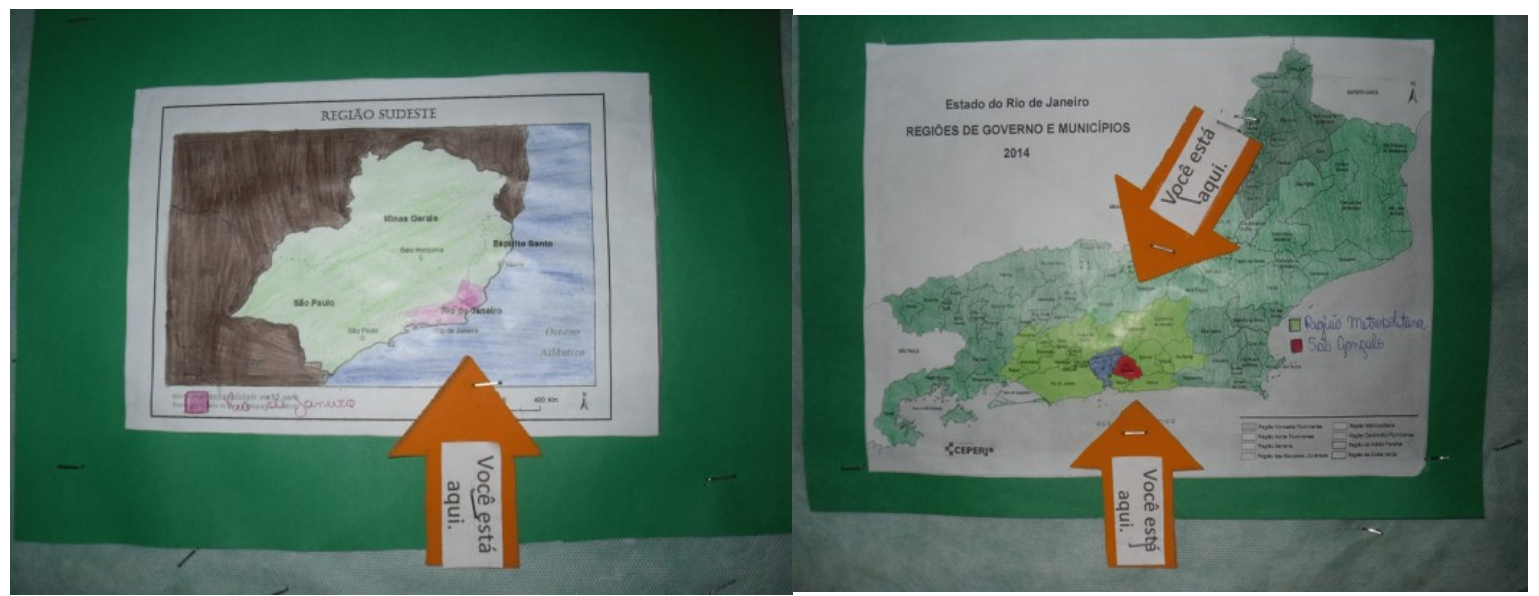




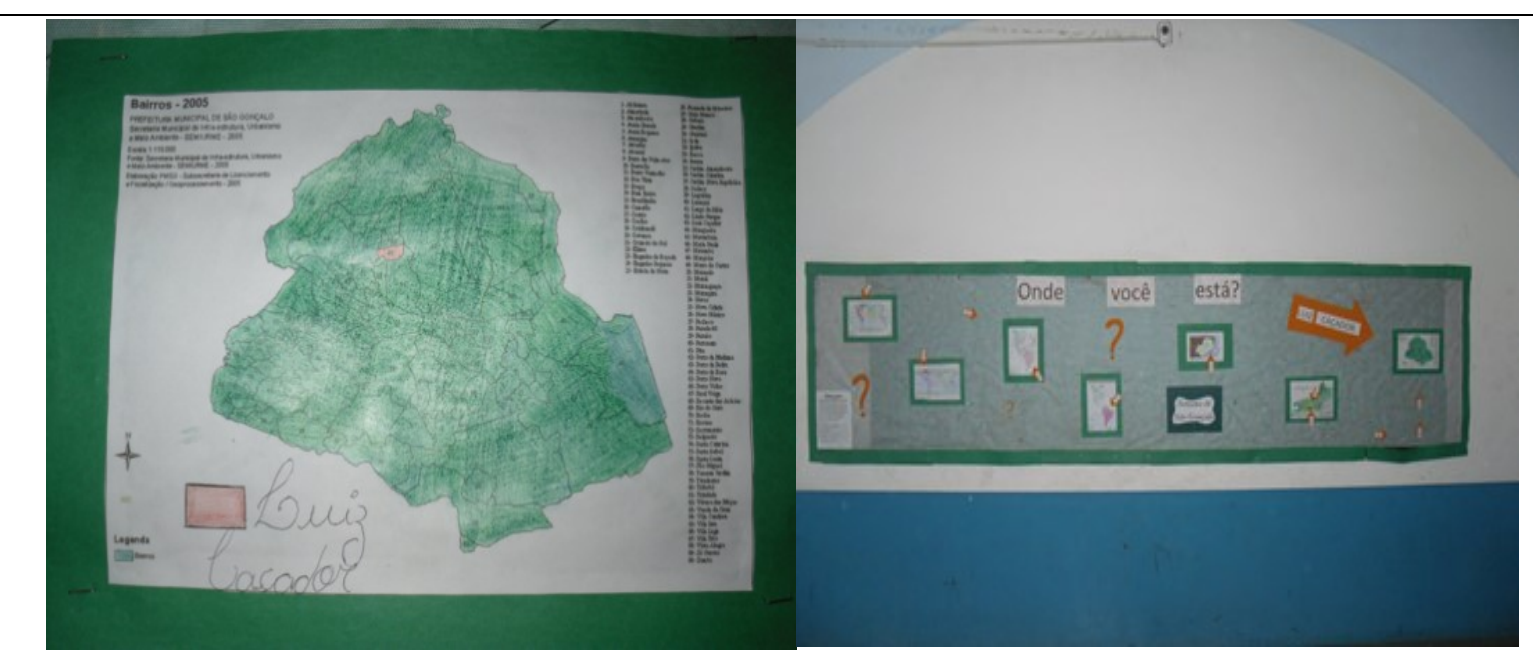

Fotos: 1, 2,3 e 4: Painéis cartográficos construídos pelos estudantes.

Fonte: Arquivo do Projeto, 2014.

\section{2) Os Problemas urbanos e ambientais de São Gonçalo}

A atividade foi desenvolvida para pensar os problemas urbanos e ambientais no município, pois todos os impactos ambientais gerados pela urbanização desenfreada causam consequências tantos para a natureza quanto para nós seres humanos. Ao abordar a cidade, os estudantes viram as suas múltiplas contradições, como enfatiza Cavalcanti (2012), que é conseqüência de um modo de produção que cria constantemente produtos a serem consumidos que requer maior uso dos recursos naturais, ocasionando, consequentemente, a destruição, depredação e poluição destes.

Eles analisaram esses impactos em seu local de vivência e se identificaram com os assuntos, pois muitos relataram fatos vivenciados por amigos e familiares, os cartazes de propaganda eleitoral que é um tipo de poluição visual que são colocados em suas ruas, casas e afins e a poluição dos rios de São Gonçalo, em que muitos residem próximo ou tem contato com o rio que passa ao lado da escola.

Para o desenvolvimento da atividade utilizou-se de alguns materiais didáticos para mediar os conhecimentos relevantes sobre a cidade: O uso das imagens, representando os principais locais de destinação de lixos, dos distintos tipos de poluições e também da enchente que ocorreu na cidade em 2010, onde os estudantes começaram a indagar, questionar e até mesmo levantar possíveis soluções para os problemas apresentados.

O uso do vídeo Jornal Nacional - JN no Ar - São Gonçalo RJ 21/09/2010 - aproximou a temática à realidade vivida cotidianamente. Porém, São Gonçalo é um município de grande porte, logo, possui em si lugares diferenciados, por isso, houve a necessidade de aumentar o detalhamento escalar do conteúdo. Sendo assim, foi passado outro vídeo para os alunos, em seguida, mostrando o alagamento que a área do bairro ao qual residiam e os bairros vizinhos foram atingidos pelas chuvas de 2010 .

A partir dessa aproximação, houve interação e participação dos estudantes que perceberam o quanto é importante a preservação do meio ambiente. Percebeu-se esses impactos em seu local de vivência e se sentiram identificados com os assuntos, pois muitos deles relataram suas experiências negativas com a situação que tiveram de passar, ocasionada pela falta de infraestrutura urbana para comportar o lixo e de fazer o descarte adequado, isso se dava a partir de uma leitura da cidade enquanto cidadãos. 
Os relatos também eram feitos sobre o fato da enchente que atingiu amigos e familiares, os cartazes de propaganda eleitoral que é um tipo de poluição visual que são colocados em suas ruas, casas e afins e a poluição dos rios de São Gonçalo, em que muitos residem próximo ou tem contato com o rio que passa ao lado da escola. Vê-se então, o papel da escola segundo Cavalcanti (2005a, 2005b, 2011), como de uma das instâncias formadoras da cidadania.

Dessa forma, pode-se perceber como afirma Castellar (2005 2011), Castellar e Moraes (2010), a Geografia ser uma disciplina escolar que o ajuda a melhorar seu conhecimento de raciocínio-lógico e espacial. Além disso, estabelecer problematizações a partir do conhecimento construído em situações mais simples às mais complexas aumenta a capacidade do aluno saber fazer. Com isso, os alunos são preparados a pensar criticamente em ambientes até mesmo fora da escola. Para tanto, seria necessárias mudanças teóricas e metodológicas no ensino. Sendo assim, "a superação do ensino descritivo está na compreensão do papel que o currículo tem na formação dos alunos, que é de trazer para a escola o conhecimento científico e ajuda a promover o desenvolvimento intelectual dos alunos".
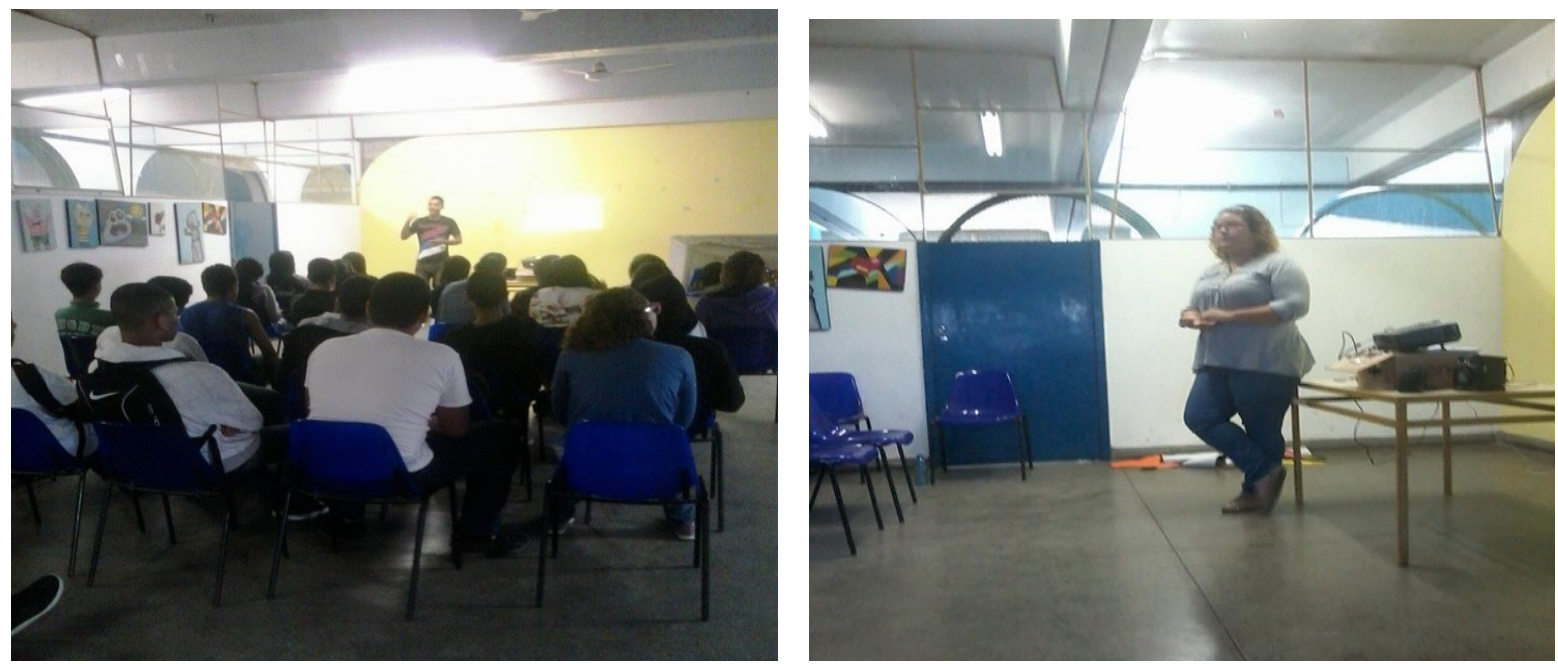

Fotos 5 e 6: Atividade sobre Problemas urbanos e ambientais de São Gonçalo

\section{3) A Modelagem de Relevo Terrestre e a relação com o lugar São Gonçalo}

O estudo do relevo é muito importante para compreender s o espaço geográfico de um determinado lugar. Sua influência sobre o clima e a vegetação nos leva a confirmar sua importância no aprendizado do aluno. O tema é importante conceito dentro da perspectiva de uma educação geográfica, pois faz parte da paisagem cotidiana dos estudantes, que precisam saber diferenciá-los.

O relevo faz parte do lugar, do cotidiano do aluno, seu lugar de pertencimento que em muitos momentos pode ser visualizado pela janela da sala de aula. Paisagens distantes e tão presentes para eles.

Como metodologia, foram desenvolvidas as atividades de aprendizagem, a partir das seguintes etapas da oficina:

1 - As imagens foram selecionadas previamente, retiradas de um livro que contém as feições ilustradas do Brasil; discutiu-se sobre como o tema seria abordado e como seria tratada a realidade dos estudantes. 
2 - Dividiram-se os mesmos em cinco grupos (com cinco cada), entregaram-se isopores já cortados em quadrados, distribuíram-se argilas, tintas e pincéis aos grupos.

3- Após a divisão e entrega dos materiais, realizou-se uma discussão sobre o relevo continental, buscando a aproximação do vivido dos estudantes, utilizando as imagens de relevo, os mesmos deveriam construir suas representações.

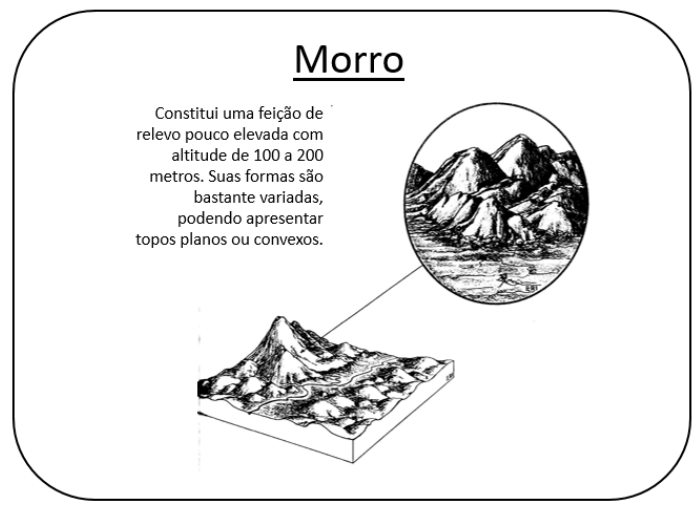

Figura 2: Morro

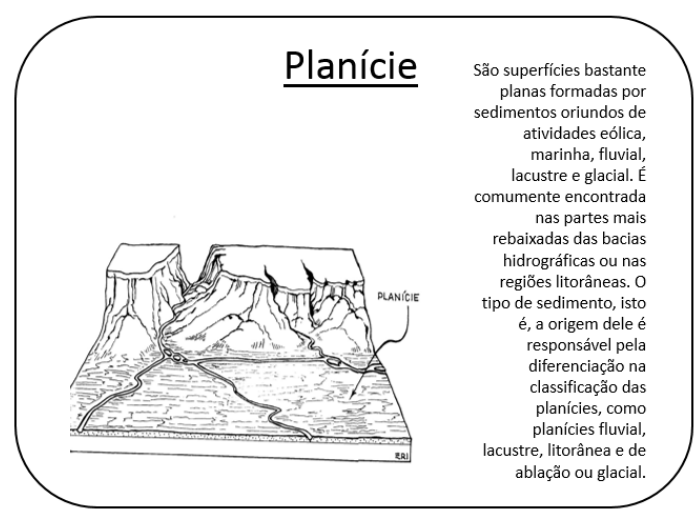

Figura 5: Planície

Fonte: SUERTGARAY (et al. , 2008)
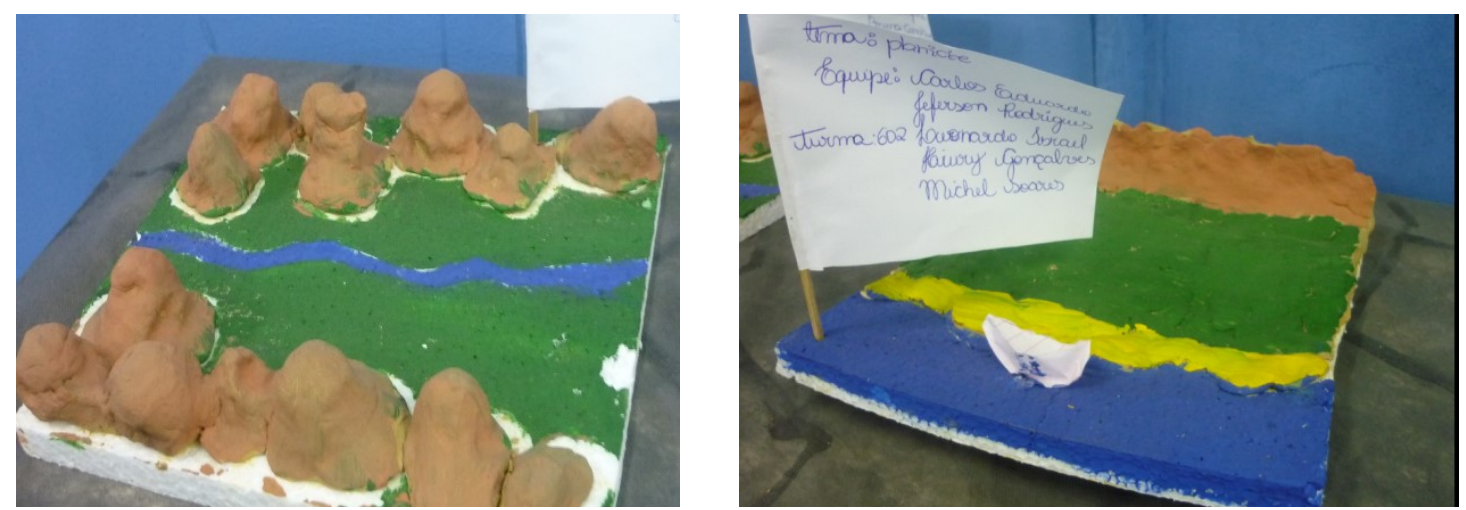

Fotos 7 e 8: Resultado das atividades sobre modelagem de relevo

Fonte: Arquivo do projeto, 2014

A partir desse produto, discutir como eles se constituem e como se apresentam nas diferentes paisagens, inclusive dos seus lugares. Os resultados alcançados foram significativos e recebidos de forma positiva por eles, pois saíram de uma educação tradicional e experimentaram uma forma diferente de se aprender. Conclui-se que, para uma educação geográfica mais significativa, o uso de métodos alternativos como a modelagem (ou outros tipos de recursos didáticos) é fundamental para uma melhor aprendizagem e para o professor se torna proveitoso ao perceber a satisfação e cooperação dos mesmos para a elaboração da atividade. 
Segundo, Suerteragay et ali (2008) entender o relevo requer a compreensão dos processos e das dinâmicas que fazem com que este se torne uma feição ou uma forma única da natureza.

Para Vega e Morais (2011), o relevo seria às diferentes rugosidades do terreno, representado, a partir da diferença de altura. Este é um elemento da paisagem físico-natural, sendo analisada, a partir da sua evolução com a interação dos diversos elementos da paisagem físico-natural.

Dessa forma, o relevo é parte constituinte do cotidiano do estudante. Em muitos locais na cidade de São Gonçalo, o relevo foi sendo alterado como o morro o localizado na Br 101 Niterói - Manilha, que foi cortado para a passagem da rodovia, como observado na altura do bairro Gradim. Nota-se que o relevo está no mesmo local há milênios e sempre trocando energia com o exterior, principalmente com elementos do clima, como as chuvas e ventos e essas trocas tem resultados que mudam a estrutura do relevo e do que está sobre ele.

Ensinar o relevo ganha importância na relação cotidiana do estudante, tanto com o bairro em que vive, como a cidade em que circula, ele experimenta fenômenos e sensações nas diversas feições e paisagens, o porquê de bairros serem mais frescos que outros, o porquê de alagamentos em alguns bairros, reflexões que só poderão ser realizadas, a partir do conhecimento prévio dos saberes e conceitos da Geografia Física.

Ou seja, compreender e ensinar com o ensino da geografia física possibilita pensar quais conceitos e conteúdos efetivamente construíram o conhecimento sobre essa temática com os estudantes, qual o sentido de estudar relevo, bacia hidrográficas, rochas, solos e outros, seus processos e suas dinâmicas da escala local como na escala global para que eles tenham consciência que vivem sobre a terra.

Ao realizar as atividades dialoga-se como as diversas formas de relevo aparecem na paisagem e principalmente, se eles observam essas formas nos seus lugares de vivência ou na própria cidade de São Gonçalo ou no Rio de Janeiro. Ao longo do processo de confecção, os mesmos refletiam sobre o tema e questionavam a influência do relevo em seu cotidiano, e até mesmo debatiam sobre outros conceitos como a paisagem e como a mesma vem se transformando ao longo do tempo: no tempo geológico e as influencias nas questões dos problemas urbanos da cidade, bem como as diversas atividades as quais os homens modificam esses relevos.

Modelar é fazer o modelo de algo que se queira representar. No ensino de geografia física, ao invés do estudante só receber o conteúdo, ele também o constrói, pois ao modelar uma forma de relevo, ele expressa o que aprendeu e como ele vê a feição representada, ele deixa de reproduzir para produzir a sua visão do que lhe foi ensinado ou apresentado. A modelagem torna-se um benefício para a representação de diversos conteúdos ministrados na aula de Geografia, de diversas realidades e de contextos sociais, das diversas paisagens encontradas em diversas partes da cidade ou até mesmo do próprio bairro.

Como resultado, pode-se dizer que os estudantes perceberam a importância do trabalho em grupo, dos conceitos e dos conteúdos da geografia física que fazem parte do ambiente local e que eles interferem na dinâmica espacial no qual os próprios vivem e que os homens modificam esses fenômenos físicos.

\section{CONSIDERAÇÕES FINAIS}

O ensino de Geografia, a partir da discussão da cidade enquanto um conteúdo de ensino, pode contribuir para melhorar a aprendizagem dos estudantes, a partir de práticas pedagógicas e metodologias novas e atualizadas para o ambiente escolar, que muitas das vezes não as possuem. 
Desenvolver na sala de aula atividades didáticas que promovem nos estudantes a possibilidade de serem participantes ativos na produção do conhecimento geográfico articulados para romper com as aulas ditas tradicionais é uma maneira de buscar dinamizar aprendizagens que sejam signfiicativas para eles.

Ensinar a cidade requer uma metodologia que possibilite articular aquilo que se ensina com aquilo que é necessário para uma prática social dos estudantes. Essa é possibilitada por uma aula mediada a partir das concepções críticas que mobilizem os estudantes a compreensão da sua realizade sócio-espacial.

Sendo assim, estudar e entender a cidade possibilita vislumbrar várias discussões acerca dos conhecimentos geográficos; viabilizar e dar significados aos lugares vivenciados; ter criticidade em relação aos fenômenos, fatos e atos que acontecem em seu redor em relação ao mundo.

Desta maneira, percebe-se com as atividades de aprendizagem trazendo a cidade de São Gonçalo enquanto conteúdo promove o desenvolvimento da escala local dos estudantes pois eles vivem os problemas, as espacialidades tratadas nos conteúdos da geografia contudo sem fazer uma relaçao com o lugar vivido. A construção de atividades que propiciem a relação com a cartografia, o relevo, os problemas urbanos ambientais permite um saber para além do tradicional conteúdo da sala de aula.

\section{REFERÊNCIAS}

ABREU, Maurício de Almeida. A Evolução urbana do Rio de Janeiro. Rio de Janeiro: IplanRIO, 1997.

CALLAI, Helena. Copetti. A articulação Teoria-prática na Formação do Professor de Geografia. In: SILVA, A. M.M. et al. Educação Formal e Não Formal, processos formativos e saberes pedagógicos: desafios para a inclusão social. Rio de Janeiro: Alternativa. 2006, p. 127-161.

Aprendendo a ler o mundo: a Geografia nos anos iniciais do Ensino Fundamenta. IN: CASTELLAR, S. (org). Educação Geográfica e as Teorias de Aprendizagens. Campinas SP: Cadernos Cedes, col 25, nº 66, 227-248 p. maio/ago. 2005.

CASTELLAR, Sônia Maria Vanzella. A Superação dos limites para uma Educação Geográfica significativa: um estudo sobre a e na cidade. San José, Costa Rica: Revista Geográfica de América Central, v. 2, 2011, p. 1-25.

(org) Educação Geográfica: a psicogenética e o conhecimento escolar. In: Educação Geográfica e as Teorias de Aprendizagens. Campinas- SP: Cadernos Cedes., col 25, no 66, .maio/ago. 2005. p. 209-225.

CASTELlAR, Sonia; MORAES, Jerusa Vilhena. Ensino de Geografia. Porto Alegre: Thompson, 2010.

CAVALCANTI, Lana de Souza. Aprender sobre a cidade: a geografia urbana brasileira e a formação de jovens escolares. San José, Costa Rica: Revista Geográfica de América Central, v. 2, 2011, p. 1-18.

Ensino de geografia e diversidade: construção de conhecimentos geográficos escolares e atribuições de significados pelos diversos sujeitos do processo de ensino. In: 
CASTELLAR, Sônia Maria Vanzella(org). Educação Geográfica: teorias e práticas docentes. São Paulo: Editora Contexto, 2005b. 66-78 p. (Geousp: Novas Abordagens)

. A Geografia Escolar e a Cidade: ensaios sobre o ensino de Geografia para a vida urbana cotidiana. Campinas-SP: Papirus, 2012.

LEFEBVRE, Henri. O Direito à Cidade. São Paulo: Centauro, 2001.

LIBÂNEO, José Carlos. Teoria Histórico-Cultural e metodologia de ensino: para aprender a pensar geograficamente. Montevidéu: Anais de 12 EGAL, 2009.

. Didática. $27^{\mathrm{a}}$ ed. São Paulo: Cortez, 2007.

MEIRIEU, Phillippe. Aprender... sim, Mas como? Porto Alegre: Artmed, 1998.

MENGA, Hermengarda. Alves. Ludke; ANDRÉ, Marli. Pesquisa em educação: abordagens qualitativas. São Paulo: EPU, 1986.

MORAIS, Eliana Marta Barbosa de. As temáticas físico-naturais no ensino de Geografia e a formação para a cidadania. Annekumene, 2011, v. 1, p. 182-193.

MOREIRA, Ruy. Pensar e ser em geografia: ensaios de história, epistemologia e ontologia do espaço geográfico. $2^{\text {a }}$ Ed. São Paulo: Contexto, 2008.

SACRAMENTO, Ana Claudia Ramos, FALCONI, Simone. Educação Geográfica e ensino de solos. Espaços da Escola (UNIJUÍ), v. 2, 2010, p. 29-42,

SANTOS. Milton. A natureza do espaço: técnica e tempo, razão e emoção. São Paulo: EDUSP, 2002.

SOUZA, Marcelo Lopes de. ABC do Desenvolvimento Urbano. $6^{\text {a }}$ ed. Rio de Janeiro: Bertrand Brasil, 2011.

O desafio metropolitano: um estudo sobre a problemática sócio-espacial nas metrópoles brasileiras. Rio de Janeiro: Bertrand Brasil, 2000.

. Urbanização e desenvolvimento no Brasil atual. São Paulo: Ática, 1996.

SUERTEGARAY, Dirce Maria Antunes (et ali) Terra Feições Ilustradas. 2a . edição. Porto Alegre: Editora da UFRGS, 2008. 361p

THIOLLENT, Michel. Metodologia da pesquisa-ação. São Paulo: Cortez, 2007.

VEGA, Alfonso Garcia. de la; Morais, Eliana Marta Barbosa. de. Desafios e possibilidades para trabalhar relevo na educação geográfica. Revista Geográfica de América Central (online), v. 1, 2011.p. 1-9

ZABALA, Antoni. A Prática Educativa: como ensinar. Porto Alegre: Editora Artmed, 2007. $2^{\mathrm{a}} \mathrm{ed}$. 